\title{
Conditions for economic competitiveness of pumped storage hydroelectric power plants in Egypt
}

\author{
Diaa Abdellatif ${ }^{1}$, Rameen AbdelHady ${ }^{2 *}$, Ahmed M. Ibrahim ${ }^{3}$ and Essam Abu El-Zahab ${ }^{3}$
}

\begin{abstract}
Pumped storage hydroelectric power plants are one of the most applicable energy storage technologies on largescale capacity generation due to many technical considerations such as their maturity, frequency control and higher ramp rates, thus maintaining following loads in case of high penetration of renewables in the electrical grid. Economic viability of PSHPPs is still questionable when compared with other electricity generation technologies. In this manuscript, the key factors that affect the viability of constructing PSHPP in Attaqa Mountain, Egypt, are defined. An economic comparison between PSHPPs and simple cycle gas turbine power plants has been carried out to identify the conditions at which PSHPPs will have competitiveness as an on-peak solution, over traditional SCGT power plants. This assessment is based on calculating levelized cost of electricity taking into account different scenarios for PSHPP pumping cost and capital cost, and different scenarios for SCGT fuel prices. The results showed the key factors of the best case at which PSHPPs have the highest economic competitiveness over SCGT power plants when fuel prices are non-subsidized. This is only valid provided that the PSHPP's capital cost should not exceed $4180 \$ / \mathrm{kW}$ at zero pumping cost.
\end{abstract}

Keywords: Pumped storage hydroelectric power plant, Levelized cost of electricity, Simple cycle gas turbine, On-peak demand

\section{Introduction}

Energy strategic planning is one of the world's main concerns to cover the fast-growing energy demand taking into account the wise use of available energy resources to achieve the optimum electricity generation mix. One of the main difficulties of energy planning for any country is selecting the most compatible alternative to fulfill its requirements, as the selected alternative will have a long-term impact on its economy and the utilization of the available resources.

The on-peak electricity demand is a challenge for grid operators because it requires special generating power plants that can directly follow the increase in demand and maintain its balance with the supply. The electricity load

\footnotetext{
*Correspondence: rameens@hotmail.com; rameen.abdelhady@gmail. com

${ }^{2}$ National Water Research Center (NWRC), Ministry of Water Resources and Irrigation, El Qanatir, Egypt

Full list of author information is available at the end of the article
}

duration curve of Egypt is not flat and consists of two major periods through the whole day: The first period is in day time from $1 \mathrm{am}$ to $7 \mathrm{pm}$ (off peak) during which the demand can be easily covered by base load generation power plants such as combined cycle, steam and simple cycle power plants, ordered, respectively, according to better economic dispatch and efficiencies and the second period is at night starting from $7 \mathrm{pm}$ to $12 \mathrm{am}$ (on-peak), as shown in Fig. 1 (EEHC 2015), at which electricity demand requires high ramp rate generation solutions (balancing the supply with the demand fluctuations over short times) that can quickly respond to the increase in that demand.

Typically, reservoir hydropower plants (HPPs) and PSHPPs supply primary control power. However, it is not the case for the Egyptian National Grid. In Egypt, the daily on-peak periods are met with peaking units, especially simple cycle gas turbine (SCGT) (specific), or using electrical interconnection between neighboring countries 


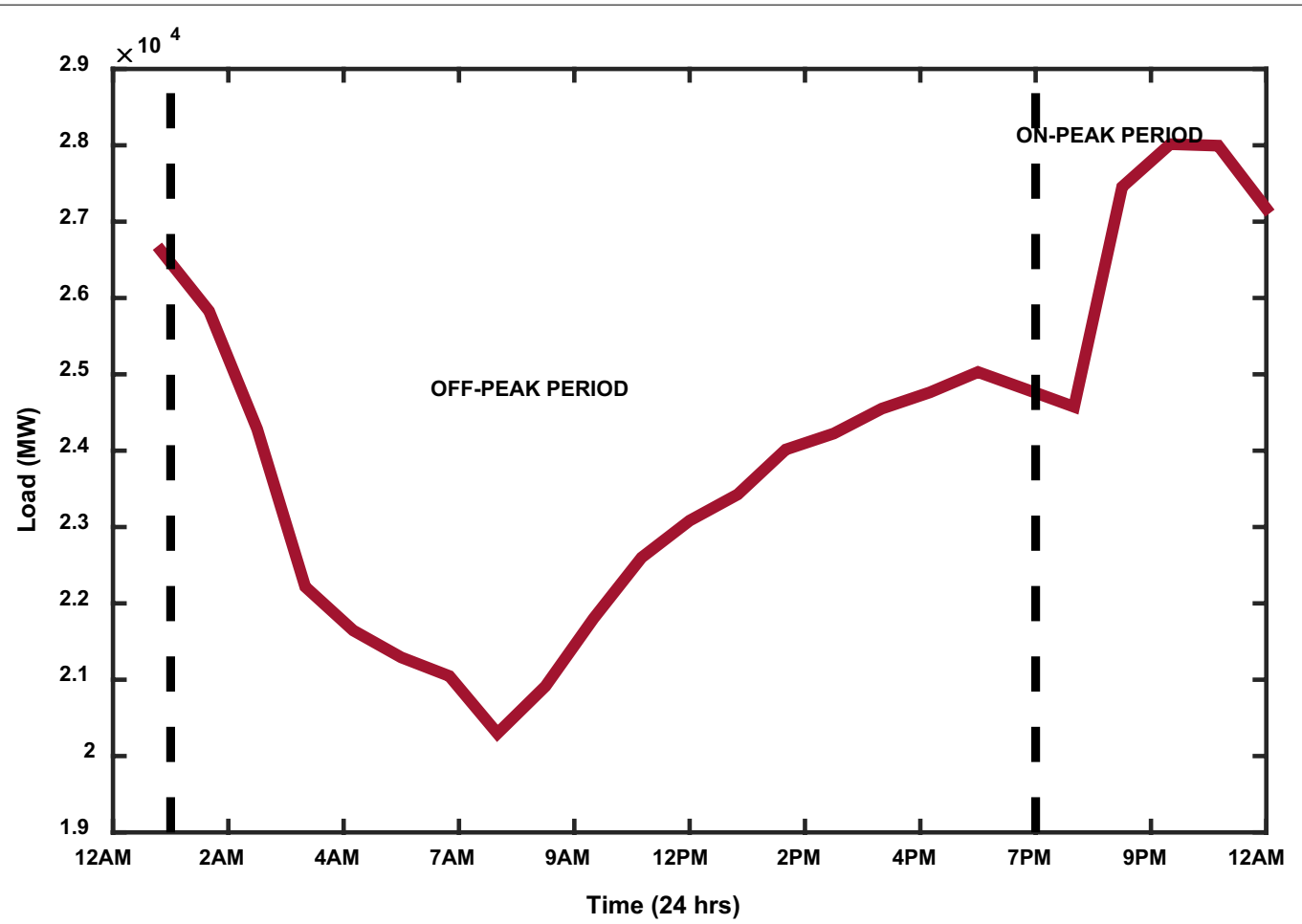

Fig. 1 Egypt load curve 2014/2015

because they can quickly start up and shut down to meet brief peaks in demand. These solutions for on-peak periods are typically the most expensive to operate when considering peaking units and have low reliability when considering interconnection because it is dependent on other countries' technical and political situations. Peaking units also serve as spinning reserve and as "quick start" units which are able to go from shutdown to full load in minutes. A peaking unit typically operates for only a few hundred hours a year. They run only as needed to meet the highest loads (Kaplan 2008).

Another solution that can cover on-peak demand through the day is electrical energy storage (EES) technologies whose operation is based on storing electrical energy when there is an excess generation then releasing this energy when needed, so this released electricity can promptly follow the electricity demand.

Many energy storage technologies are technically applicable, but they still have challenging issues related to the scale of their use, their capital costs and the installing site selection. Another challenge of energy storage technologies is the loss between charging and discharging energy that requires a specific technique of pricing and new energy market rules, thus increasing their economic viability.
This energy storage technology can provide two main services: supplying electricity during on-peak or high ramp demand rates and putting off some capacity expansions in the electrical grid.

EES technologies can be classified into different categories [Fig. 2 (OWOE 2014)] according to their suitable storage durations, response times, functions or the form of energy they store.

One of the EES technologies is pumped hydro storage. In 2011, the International Hydro Power Association (IHA) estimated that pumped hydro storage capacity to be between 120 and 150 GW (IRENA 2012) with a central estimate of $136 \mathrm{GW}$. In 2014, the total installed capacity of pumped storage hydroelectric power plants (PSHPPs) around the world reached $140 \mathrm{GW}$, which is very large compared to other EES technologies (976 MW) (IEA 2014). Pumped storage represents about $2.2 \%$ of all generation capacity in the USA, $18 \%$ in Japan and 19\% in Austria (IRENA 2012). According to energy storage exchange Web site statistics (Sandia National Laboratories 2016) in 2016, there are about 7 projects under construction until 2018 with a total capacity of $5.95 \mathrm{GW}$ including 4 projects in Africa with total capacities of $2.05 \mathrm{GW}$ in both Morocco and South Africa. There are many studies that have been done on different 


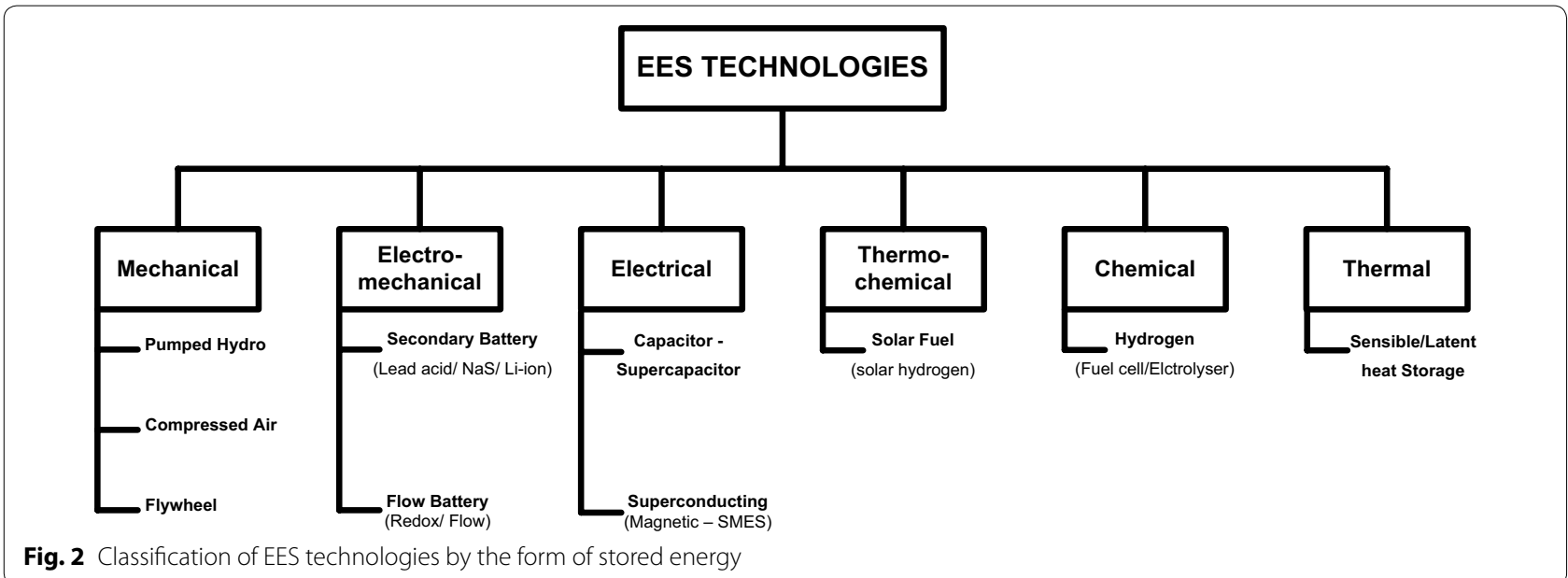

sites to construct a PSHPP in Egypt. The most viable site was found to be Attaqa Mountain (Fig. 3), based on the techno-economic study which has been done by a Swedish Consultant (SWECO 1997).

According to this study, the site can involve six reversible turbines (overall flow rate $318 \mathrm{~m}^{3} / \mathrm{s}$ ) with a total power capacity of $2100 \mathrm{MW}$ with an upper reservoir, of $9 \mathrm{mcm}$ volume capacity, at a height of $850 \mathrm{~m}$. The horizontal distance between the upper and the lower reservoir is expected to be $1450 \mathrm{~m}$; hence, the effective head is $600 \mathrm{~m}$.

There are six vertical steel lined penstocks (with inner diameter of $3.6 \mathrm{~m}$ ) for the flow of water up and down between the reservoirs, linked two by two to horizontal circular concrete lined tunnels with larger diameters. The access to the underground power plant is by a long tunnel, while there are three horizontal lower tunnels between the lower reservoir and the turbines. There will

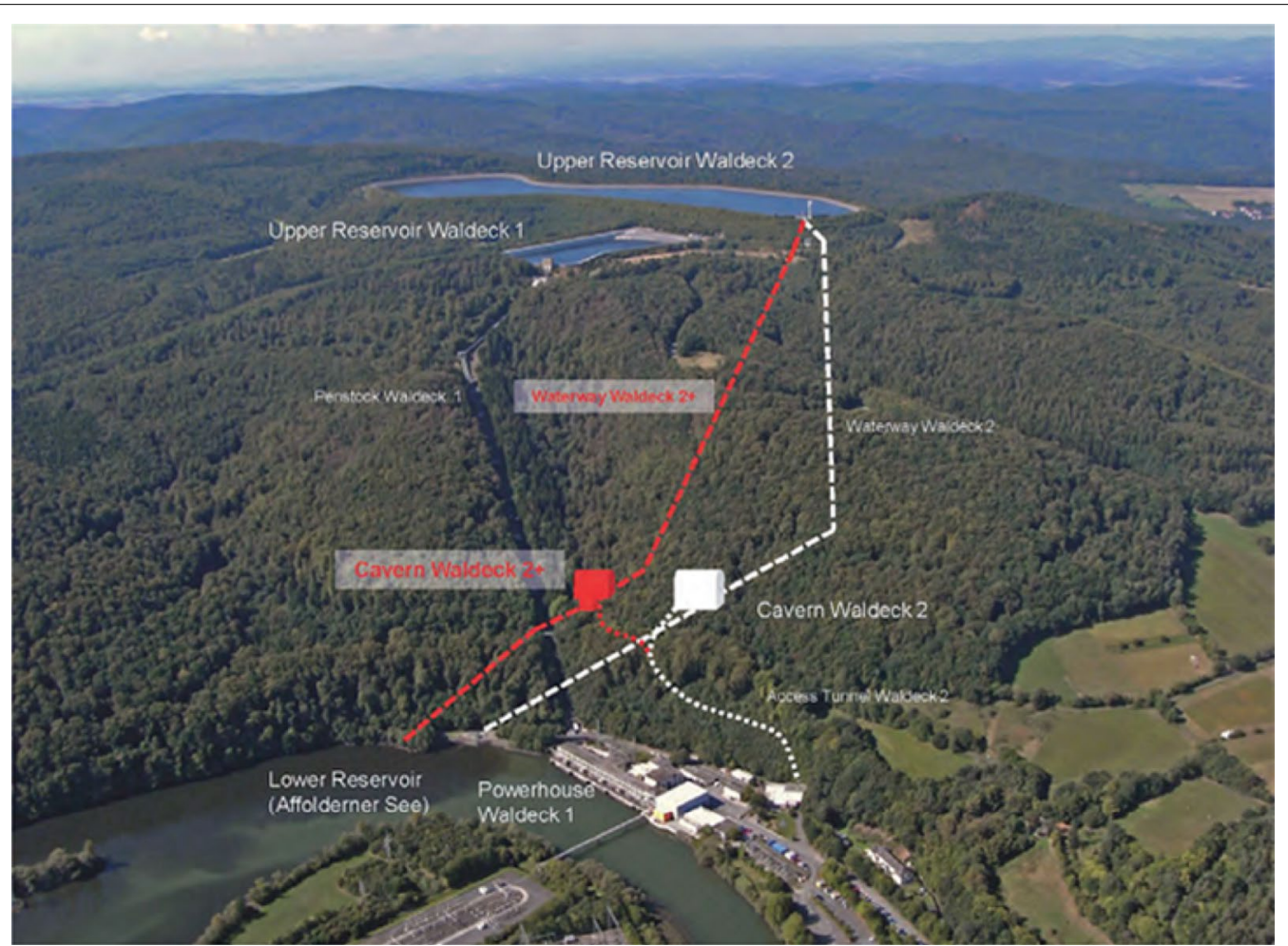

Fig. 3 PSHPP of Attaqa Mountain, Egypt 
be a machinery hall (180 m long and $16 \mathrm{~m}$ wide) and a specific area (175 m long and $15 \mathrm{~m}$ wide) to include the power transformers (SWECO 1997).

The basic concept of PSHPPs involves pumping water from a lower reservoir for storage into an upper reservoir, then generating electricity by using the same water flowing from the upper reservoir through turbine generators back into the lower reservoir as shown in Fig. 4 (OWOE 2014). The cycle is repeated on daily or weekly basis.

This process can be operated using a reversible turbine to pump up water. The turbine is connected to a motor for generating electricity. The efficiency of PSHPPs to make full water cycle (cycle efficiency) ranges typically between 70 and 85\% (Barbour et al. 2016). Therefore, the required energy to pump up water is higher than the generated energy from PSHPP by $15-30 \%$ due to losses, which is what the debate of PSHPPs is about. This can be solved by different tariff mechanisms (e.g., double tariff structure). Double tariff is the two times of use tariff (ToU) and it has two fixed values over the day based on times of configuration.

It is also possible to get benefit of excess electricity during lower-demand periods to charge water into upper reservoirs then this water can be discharged down to start up a turbine to generate electricity during the highdemand periods. The economic benefit of PSHPPs comes from pumping with low-cost off-peak and generating onpeak to displace high-cost energy, to reduce total generation cost by time shifting (IEC 2011). Moreover, PSHPP plays an important role in providing power factor correction and voltage regulation in the generating or pumping mode and they can also operate unloaded as synchronous condensers, thus enhancing the electrical power system stability.

The first designs of PSHPPs in the 1890s used separate pump motors and turbine generators. Since the 1950s, a single reversible pump turbine has become the dominant design for PSHPPs (Baxter 2006).

PSHPP has some advantages, when compared with SCGT power plants to cover the on-peak electricity demand; one of these advantages is that PSHPPs do not have the capacity reduction experienced by combustion turbines due to high ambient temperature, and at the same time, it has a higher reliability than combustion turbines. Other benefit of PSHPPs is their lifetimes because hydropower plants usually have very long lifetimes (in the range of $30-80$ years) and their components can be sustained in operation (IRENA 2012).

Energy storage also has an important role in the efficient utilization of electricity from renewable energy resources. Many renewable energy resources, such as wind, solar, HPPs and tidal energy, are variable and inconstant and so are unable to supply electrical power continuously. Integrating some energy storage with renewable resources improves the expected generated energy from renewables, removes their uncertainties and increases the value of the electricity generated (Breeze 2014).

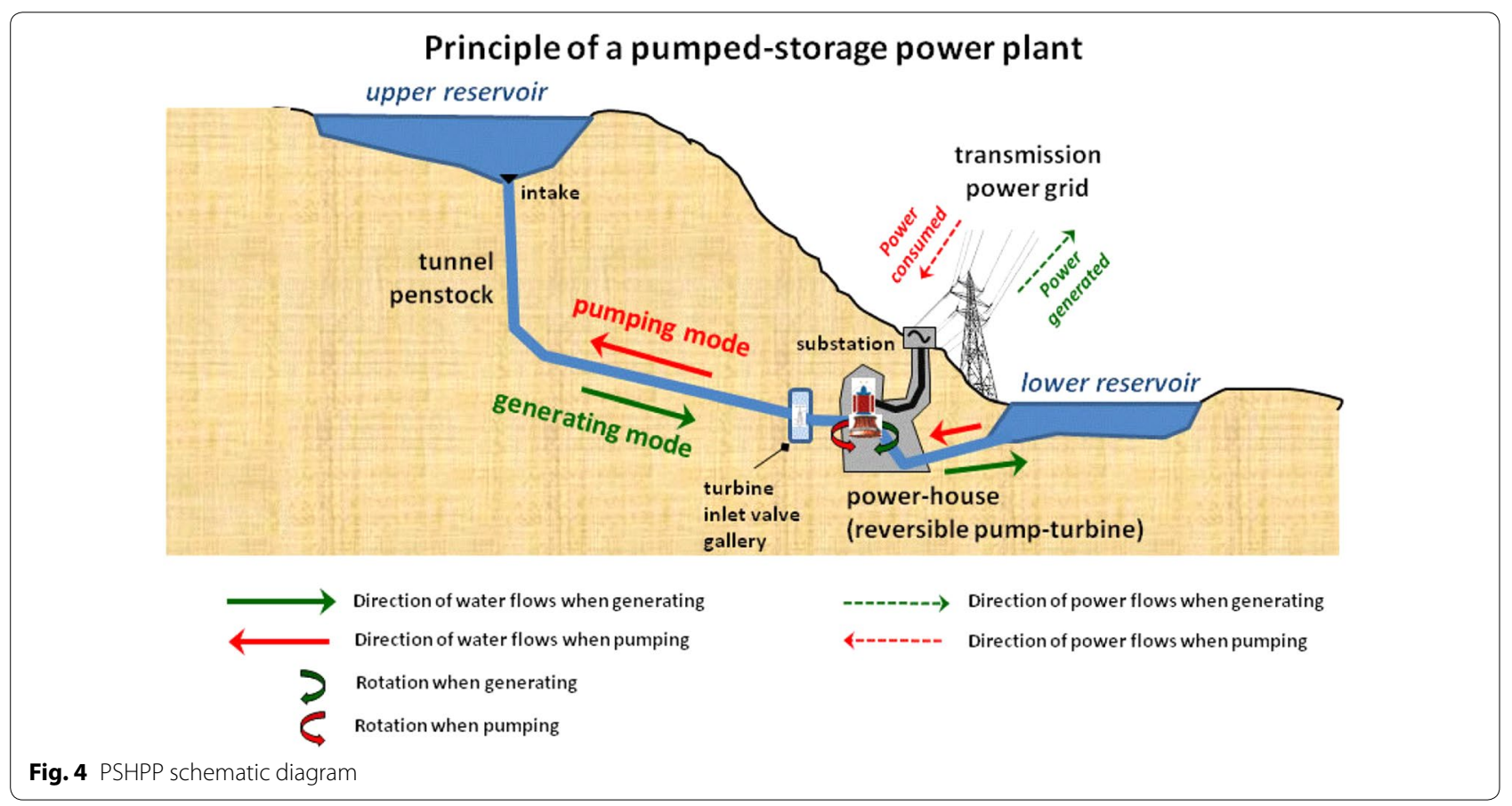


Although PSHPP and SCGT are technically viable to operate as on-peak generation power plants, the economic drawbacks of PSHPP due to its high capital cost and its cycle efficiency limit its feasibility. In this manuscript, a comparison of both PSHPP and SCGT in Egypt is presented. This comparison is based on a standard levelized cost of energy (LCOE) approach that enables decision makers to compare between different technologies of diverse lifetimes, capacities, heat rates and other specifications, to choose the most economic technology in \$/ $\mathrm{kWh}$. LCOE is the summation of all the costs that are borne through a generating technology lifetime divided by the energy generated from that technology and is expressed in $\$ / \mathrm{kWh}$.

The time value of money concept is also taken into consideration in calculating LCOE represented in the discount rate $(r)$ which mathematically refers to the interest rate used to calculate the present value of future cash flow. LCOE of PSHPP and SCGT is calculated based on financial modeling, using Microsoft Excel spreadsheets, taking into consideration the different technical and economic aspects of each technology such as heat rate, lifetime, capacity factor, fixed and variable O\&M and capital costs. An analysis of different scenarios is also performed to define the conditions at which PSHPP has competitiveness over SCGT power plants. These cases include scenarios for PSHPP pumping cost and scenarios for SCGT fuel costs which have a significant impact on the LCOE of both power plants; also, different values of $r$ are considered. This is a simplified approach, as PSHPPs have many additional features of their operation in the common grid. The cost estimate of those features cannot be represented so easily, but they are of crucial importance for the parameters of the grid and PSHPPs operation.

\section{Methodology}

The calculation of LCOE for PSHPP and SCGT includes the capital investment costs, operation and maintenance costs and different discount rates. Other LCOE elements such as pumping cost of PSHPP and fuel costs of SCGT were calculated under different scenarios.

\section{PSHPP LCOE calculation}

To calculate the PSHPP's LCOE, the following equation is used:

$$
\mathrm{LCOE}=\sum_{t=1}^{n} \frac{I_{t+M_{t}+P_{t}}}{(1+r)^{t}} / \sum_{t=1}^{n} \frac{E_{t}}{(1+r)^{t}}
$$

where LCOE is levelized cost of electricity generated from PSHPP in $\$ / \mathrm{kWh} ; I_{t}$, project investment costs needed to construct the PSHPP in the year $t$ in \$; $M_{t}$, operation and maintenance cost in a certain year $t$ excluding pumping cost in $\$ ; P_{t}$, pumping costs in the year $t$ in $\$ ; E_{t}$, the electricity generation in the year $t$ in $\mathrm{kWh} r$, discount rate; and $n$, expected PSHPP lifetime in years.

In general, the term $\sum_{t=1}^{n} \frac{I_{t+M_{t}+P_{t}}}{(1+r)^{t}}$ refers to the discounted project lifetime costs, while the term $\sum_{t=1}^{n} \frac{E_{t}}{(1+r)^{t}}$ represents the discounted project lifetime generated energy.

According to Eq. (1), the main elements required to calculate PSHPP's LCOE during its lifetime are:

- Capital investment costs.

- Operation and maintenance costs (O\&M).

- Pumping cost.

- Discount rate $(r)$.

\section{Capital investment costs}

The investment costs are those costs needed to construct PSHPP including all capital costs (overnight costs) and the required investments to cover them. These costs are required mainly for: engineering, procurement and construction works of PSHPP including civil, mechanical and electrical works.

The breakdown of PSHPP capital costs follows the plant component decomposition:

- Electromechanical system comprising turbines, actuators, regulators, generators, circuit breakers, a grounding system and a protection system;

- Control and monitoring system including supervisory control and data acquisition (SCADA); and

- Water supply system containing water depressing and drainage systems.

Other costs included in the capital investment cost are civil works, the cost of interconnecting the PSHPP to the grid and the water and piping system.

Civil works Due to the topography of the site, SWECO International's study (SWECO 1997) assumed this civil cost to count an amount of $25 \%$ of the total project capital cost. The tunnel cost is a very large part of the civil works; therefore, it is important to find the tunnel cross section that gives the lowest cost (Rognlien 2012). Optimization of the tunnel cross section was elaborated by SWECO (SWECO 1997); for further details, refer to (SWECO 1997). The cost of interconnecting the PSHPP to the grid:

Based on data from Egyptian Electricity Transmission Company, the average cost of a $500 \mathrm{~V}$ three phase transmission line is $0.4 \mathrm{M} \$ / \mathrm{km}$ with a capacity of $1750 \mathrm{MVA}$. The $2100 \mathrm{MW}$ PSHPP will need three transmission lines to be able to absorb/evacuate electricity from/to the 
Egyptian Unified Grid. Another extra bundle of three phase transmission line type is assumed to be interconnected with the PSHPP for emergency. The nearest point to the Egyptian Unified Grid that the PSHPP can be interconnected is at a distance of $8 \mathrm{~km}$. According to these assumptions, the total interconnection cost in the study will amount to $12.8 \mathrm{M} \$$.

Water and piping system PSHPP will need a large volume of water at the start-up, to run the PSHPP with its full power capacity. This water volume amounts to $9 \mathrm{mcm}$ (SWECO 1997). This volume acts as an active volume of the upper reservoir, bearing in mind that there will be daily evaporation, which can be calculated according to the annual evaporation rate in Suez $(3400 \mathrm{~mm} /$ year) (Edgell 2006). The leakage expected during operation was also taken into account, so the total daily backup water amount is assumed to be $10^{4} \mathrm{~m}^{3} /$ day.

The total cost of water needed for operating of the PSHPP is calculated according to Eq. (2):

$$
\text { Water cost }=\left(\mathrm{UR}_{C}+N \times W_{l}\right) \times P_{w}
$$

where water cost is cost of water required to fill in the upper reservoir during a certain number of years in $\$ ; \mathrm{UR}_{c}$, upper reservoir water capacity in $\mathrm{m}^{3}$; $W_{l}$, annual loss of water due to evaporation in $\mathrm{m}^{3} ; \mathrm{N}$, the number of construction years discarding 1 year for filling the upper reservoir (4 years in this case); and $P_{w}$, price of $1 \mathrm{~m}^{3}$ of water in $\$$.

PSHPP has a site specific capital investment cost, which is significantly variable from one site to another; the above costs are site specific to the area of Mount Attaqa in Egypt. This unpredictability in the capital investment costs is mainly due to the changing civil works costs, where the plant component cost variability is slight. In this study, the cost of plant components is assumed to be fixed at $1600 \$ / \mathrm{kW}$, while the civil works cost varies from 600 to $3600 \$ / \mathrm{kW}$ at a fixed step of $200 \$ / \mathrm{kW}$ to generalize the analysis. This assumed range is made to acquire the minimum and maximum possible values of LCOE of the PSHPP in Egypt based on the world's lowest and highest figures of constructing such kind of power plants (2200-5200 \$/kW including the costs of plant components). The cost of interconnecting the PSHPP to the grid and the cost of water and piping system per $\mathrm{kW}$ is included in the variable number of civil works to sum up the value of the capital investment cost.

All the above-mentioned costs were assumed as the total fixed capital costs required to completely construct the PSHPP; however, there are extra costs that will be incurred to secure financing to all these capital costs. The finance structure of the PSHPP was assumed to be divided into two debt loans as follows:
Loan from local banks It amounts $40 \%$ of the total project capital costs to be repaid over 10 years with an annual interest rate of $11 \%$ and grace period 2 years with a commitment fee $0.5 \%$ on the remaining balance at each year during the construction period of the project.

Loan from foreign banks It amounts $60 \%$ of the total project capital costs to be repaid over 20 years with an annual interest rate of $6 \%$ and grace period 3 years with a commitment fee $0.5 \%$ on the remaining balance at each year during the construction period of the project.

\section{Operation and maintenance (O\&M) costs}

The O\&M costs are those costs needed to ensure the proper operation of the PSHPP and are divided into fixed O\&M costs and backup water costs.

Fixed OEM costs These costs were assumed to be $30.8 \$ / \mathrm{kW}$ annually according to Black and Vetch Consultancy Company projections report of performance and cost data for power plants (Black and Vetch 2012). These costs include the wages and salaries of the PSHPP operators and engineers as well as the spare parts and the refurbishment of mechanical and electrical equipment.

Backup water cost As stated above, PSHPP will require backup water during PSHPP operation to recover the evaporated amounts and its cost is included in the operational costs. The cost of backup water is calculated using Eq. (2) taking into account that the number of years $(N)$ will be 1 because this cost will be encountered annually. The upper reservoir water capacity $\mathrm{UR}_{c}$ term in the equation will be equal to zero because the loss in water is only calculated. $P_{w}$ is assumed to be escalated annually during the lifetime of the PSHPP by $3 \%$ following the consumer price index (CPI) in USA which amounted $2.34-2.39 \%$ in 2015 (Trading Economics 2016).

\section{Pumping cost}

Pumping cost is the cost of electricity that will run the PSHPP in pumping mode to lift up water from the lower reservoir to the upper reservoir during off-peak times. This cost will differ based on the following scenarios (Fig. 5):

First scenario The pumping cost is assumed to be equal to the price of buying electricity from the Egyptian Unified Grid at off-peak time on the extra high voltage level $(220 \mathrm{kV})$ and this cost will include capacity payments (1.54 \$/kW Month) and energy payments $(0.0248 \$ / \mathrm{kWh})$ (EgyptERA 2015). 


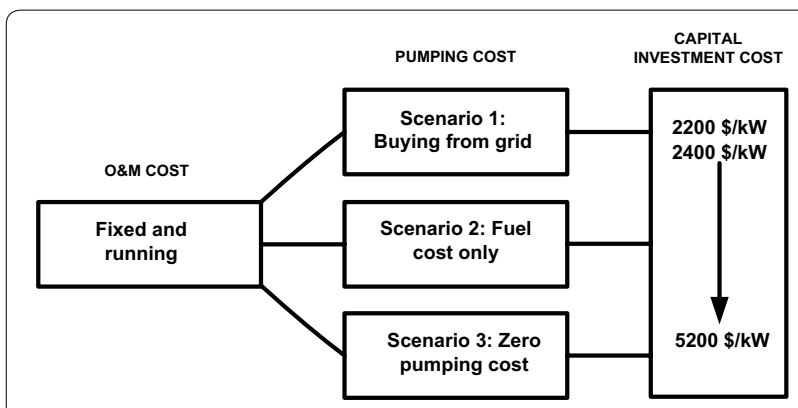

Fig. 5 Pumping cost scenarios in combination with different investment/capital costs

Second scenario The pumping cost is assumed to be $70 \%$ of the total energy payment cost in the first scenario $(0.01736 \$ / \mathrm{kWh})$, while this percentage represents the average cost of fuel usage in electricity generation according to the Egyptian Electricity Holding Company (EEHC).

Third scenario The pumping cost is assumed to be zero. This assumption is based on supplying electricity for pumping, from renewable power plants that are connected to grid and do not generate electricity during peak times, or from the available spinning reserve from the traditional thermal power plants during off-peak time.

The pumping cost is assumed to be escalated by $3 \%$ annually over the project lifetime in the first and second scenarios.

\section{Discount rate}

The discount rate is the opportunity cost of capital or in other words is the return on investments foregone elsewhere by committing capital to the project under consideration. Mathematically, it refers to the interest rate used to calculate the present value of future cash flow in a discounted cash flow (DCF) analysis. It is used to take into account not only the time value of money, but also the uncertainties and risks the cash flow may suffer from in the future; the higher the expected risks and uncertainties in the future, the higher the discount rate is expected. The future value of a cash flow at certain specific period (year, month or day) can be discounted using a discount factor (DF) which is the amount by which any future value must be multiplied to convert it into present value and it can be calculated using Eq. (3):

$$
\mathrm{DF}=\frac{1}{(1+r)^{t}}
$$

where DF is discount factor; $t$, number of periods (years) separating the future and present value; and $r$, the discount rate.
In some studies, the discount rate used for a project is considered equal to the project weighted average cost of capital (WACC) and this is when discounting the cash flow from a utility or firm point of view. Typically, a utility finances its assets and projects either through debt, bank loans, bonds. WACC is the weighted average of costs related to financing a certain project from loans (Deloitte 2014).

The general formula used to determine the average cost of raising capital through debt (WACC) is:

$$
\mathrm{WACC}=\left(L_{\mathrm{LB}} \times \mathrm{IR}_{\mathrm{LB}}+L_{\mathrm{FB}} \times \mathrm{IR}_{\mathrm{FB}}\right) \times\left(1-T_{c}\right)
$$

where WACC is weighted average cost of capital; $L_{\mathrm{LB}}$, percentage of the loan from local banks; $\mathrm{IR}_{\mathrm{LB}}$, annual interest rate on the loan from local banks; $L_{\mathrm{FB}}$, loan from foreign banks; $\mathrm{IR}_{\mathrm{FB}}$, annual interest on the loan from foreign banks; and $T_{c}$, corporate tax rate.

According to the WACC in Eq. (4) and based on the study assumptions, the PSHPP project is totally financed by two debt loans. The corporate tax is assumed zero because such kind of power plants are normally executed by the governmental sector. According to this, the WACC value $8 \%$ is assumed to be the discount rate of the study for both PSHPP and SCGT LCOE.

From a national point of view, the discount rate value can be equal to the country's discount rate which includes all financial risks related to the country, such as credit rating and risk premium. The Central Bank of Egypt (CBE) announced in 2015 a discount rate of $9.75 \%$ (almost 10\%). Consequently, $r$ values of $10 \%$, besides the $8 \%$, as well as two other values of 12 and $14 \%$, representing pessimistic cases, were taken into consideration. It should be noted that a higher risk may be encountered because PSHPP has a long lifetime (over 60 years).

\section{General assumptions}

There are other assumptions that have been taken into account in calculating LCOE for PSHPP including its lifetime which is assumed to be 60 years (IRENA 2012), supposing the operation of the PSHPP to start at the end of the year 2020 taking 5 years as a construction period for PSHPP. The PSHPP is expected to deliver energy for $10 \mathrm{~h}$ a day (EBASCO 1993). This assumption is for design purposes.

The forced outage rate, which is the shutdown condition of a power station due to unexpected breakdown is assumed to be 5\% (Thapar 2002) and the scheduled maintenance period is 20 days a year; therefore, the availability factor of the PSHPP is calculated using Eq. (5) (34.1\%).

$$
\mathrm{AF}=\left(\frac{\left[H_{d} \times(1-\mathrm{FOR}) \times 365\right]-\left(N_{d} \times 24\right)}{8760}\right)
$$


where AF is availability factor of PSHPP; $H_{d}$, expected operating hours of PSHPP per day; FOR, expected forced outage rate; and $N_{d}$, number of days of scheduled maintenance.

Therefore, the total annual electrical energy $\left(E_{t}\right)$ generated is calculated (6274 GWh) using Eq. (6).

$$
E_{t}=(P \times \mathrm{AF} \times 8760)
$$

where $E_{t}$ is annual energy generated; $P$, output power capacity; and AF, availability factor of PSHPP.

On the other side, the electrical energy needed to pump up water to the upper reservoir is calculated as 8375 GWh (Eq. 7), assuming PSHPP typical cycle efficiency 0.75 .

$$
\eta=\frac{E_{t}}{E_{p}} .
$$

where $\eta$ is cycle efficiency; $E_{t}$, annual generated energy from PSHPP; and $E_{p}$, annual energy needed to pump up water.

This is a simplified representation. It should be noted that in this connection, several lines of financial project development are running parallel: design, administration and permits, construction, supply and installation of equipment, and more complicated financing processes are included.

\section{LCOE calculations for SCGT}

The formula used for calculating the LCOE of SCGT power plant is:

$$
\mathrm{LCOE}=\sum_{t=1}^{n} \frac{I_{t+M_{t}+F_{t}}}{(1+r)^{t}} / \sum_{t=1}^{n} \frac{E_{t}}{(1+r)^{t}}
$$

where all the terms of the equation are similar to Eq. (1) except $F_{t}$ which represents the fuel costs in the year $t$ in $\$$.

According to Eq. (8), the main components required to calculate LCOE for SCGT power plant during its whole lifetime are:
- Capital investment costs.

- Operation and maintenance costs (O\&M).

- Fuel costs.

- Discount rate.

These components are clarified below in detail with explanation to the scenarios applied for fuel cost as one of the main affecting components on the LCOE of SCGT power plant. Within each scenario for fuel cost, there will be only one value for LCOE (Fig. 6).

\section{Capital investment cost}

Capital investment cost of SCGT power plant does not vary much from one site to another within the same country, in contrast to capital investment cost of PSHPP which is site specific. Therefore, one average value for capital investment cost of SCGT will be used in the study which is $968 \$ / \mathrm{kW}$. This value, according to the Annual Energy Outlook 2015 (EIA 2013), represents an average for utility scale SCGT power plants electricity projects.

The above-mentioned capital investment cost is the overnight costs required to completely construct an SCGT power plant and this cost is assumed to be financed by two debt loans as follows:

Loan from local banks It amounts $20 \%$ of the total project capital costs to be repaid over 10 years with an annual interest rate of $11 \%$ and grace period 2 years with a commitment fee $0.5 \%$ on the remaining balance at each year during the construction period of the project.

Loan from foreign banks It amounts $80 \%$ of the total project capital costs to be repaid over 20 years with an annual interest rate of $6 \%$ and grace period 3 years with a commitment fee $0.5 \%$ on the remaining balance at each year during the construction period of the project. A different financing structure for SGT from that of PSHPP ( $60 \%$ foreign loan $+40 \%$ local loan) is assumed, due to

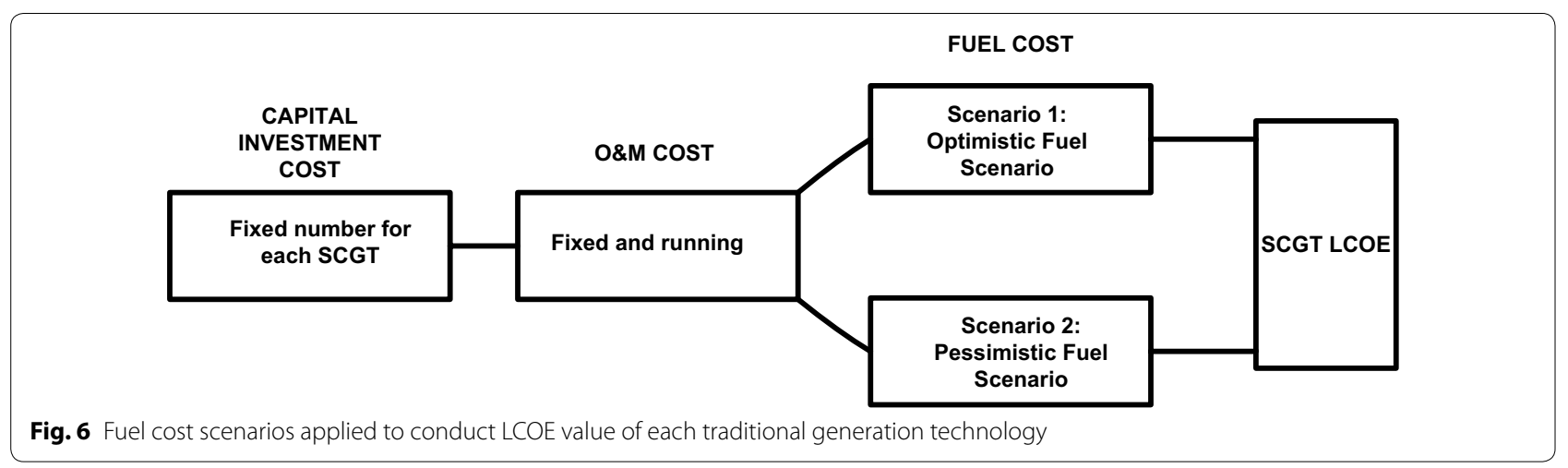


the fact that PSHPP construction has many local works such as civil infrastructure, drillings and piping systems.

\section{Operation and maintenance (O\&M) costs}

The O\&M costs can be classified into fixed O\&M and non-fuel variable $O \& M$. The fixed $O \& M$ cost includes all costs that are independent of the electricity generation production of the SCGT power plant such as wages. The annual fixed cost for SCGT used in this study is $7.34 \$ / K W$ (EIA 2013). The non-fuel variable O\&M cost includes all costs that are dependent on the electricity production level such as equipment outage maintenance, utilities and consumables such as chemicals. According to (EIA 2013), the variable cost used in calculating LCOE of SCGT is $15.44 \$ / \mathrm{MWh}$.

\section{Fuel costs}

Fuel prices are one of the key factors that affect the LCOE of the SCGT power plant when compared to LCOE of PSHPP. Natural gas (NG) is the main fuel used for electricity generation in SCGT power plant, while light fuel oil (LFO) is the emergency fuel used in the case of unavailability of NG. It is assumed that the fuel used in SCGT is $90 \%$ NG, while the residual $10 \%$ is LFO in case of emergencies. NG and LFO can be provided through local resources in Egypt or through import. If the government continues to subsidize local fuel prices supplied to the electricity sector in Egypt, it is expected that there will not be an economic competitiveness of PSHPP over SCGT. According to the Egyptian Government, by 2020 subsidies on fuel prices will be completely eliminated. Since 2016, fuel prices have been doubled and more increase is expected by the next few years. Thus, the realistic economic situation is represented using international fuel prices. Two scenarios of international fuel prices in calculating the LCOE of SCGT are studied:

- International fuel prices are assumed fixed over the different technologies lifetime based on year 2014 prices for NG and year 2015 prices for LFO.

- International fuel prices are assumed to be annually escalated by $3 \%$ over the different technologies lifetime based on year 2015 prices.

The international fuel price of NG was 8.22 \$/MBTU in 2014 according to ICIS Heren Energy Ltd. (ICIS 2016). NG drastically dropped to its lowest levels in 2015 since
1999 and such a drop in price was assumed as an odd situation due to political issue. So calculations of LCOE of SCGT were based on the 2014 price of NG, while the average international price of LFO was 12 \$/MBTU in 2015. The subsidized local prices of NG and LFO were only 37 and $43 \%$ of their international prices, in 2015 (Insee 2016). There are many factors that can affect the amount of fuel consumed by technology to generate electricity; some of these factors are the fuel type represented in its heating value and the efficiency of the technology or power plant represented in its heat rate (EIA 2016). The amount of fuel needed to generate a specific amount of electricity $(\mathrm{kWh})$ from fossil fuel fired power plant is calculated using Eq. (9) as follows:

$$
\mathrm{FA}=\frac{\mathrm{HR}}{\mathrm{HC}} \times E_{t}
$$

where FA is amount of fuel needed to generate a specific amount of electricity in $\mathrm{m}^{3}$; HR, heat rate of fossil fuel fired power plant in BTU/kWh; $\mathrm{HC}$, fuel heat content in $\mathrm{BTU} / \mathrm{m}^{3}$ for NG and in BTU $/ \mathrm{kg}$ for LFO; and $E_{t}$, the generated electricity in $\mathrm{kWh}$. The heating values used in the study are $33,723 \mathrm{BTU} / \mathrm{m}^{3}$ for NG and $41,960 \mathrm{BTU} / \mathrm{kg}$ for LFO, while the average heat rate of SCGT is 10,783 BTU/ $\mathrm{kWh}$ according to data available from EEHC (EEHC 2015).

\section{Discount rate}

Similar to that of the PSHPP, the values of $r$ were assumed to be $8,10,12$ and $14 \%$. All the study calculations will be in foreign currency US dollars (\$) using the exchange rate to convert between the local currency in Egyptian pounds (L.E.) and US dollars as 10 L.E./\$. This exchange rate is assumed to be fixed over the project lifetime and is applied at the start of year 2015, which is the base year for the study.

The currency exchange rate may have a significant effect on the project capital cost during the construction period and a slight effect during the PSHPP operation. This is because the components that will be imported from outside using foreign currencies for construction and maintenance purposes during process of installation. Accordingly, contingencies and escalation rates were taken into consideration to overcome such exchange rate issues. The escalation rates in O\&M during the project lifetime were assumed to be $3 \%$ annually. Thus, the assumption of $3 \%$ as escalation rate in O\&M is a reasonable assumption for all O\&M costs of PSHPP and SCGT and for pumping cost too. 
For each scenario and specific discount rate $(8,10,12$ and 14\%), the relation between the LCOE of PSHPP and the capital investment cost ranging between 2200 and $4200 \$ / \mathrm{kW}$ is fitted through regression (using least square method). The LCOE of SCGT is to be used to determine the competitiveness range allowed for PSHPP's capital investment costs. The relationship is fitted such that the investment cost is the dependent variable, while the LCOE is the independent variable.

Table 1 shows a summary of all the assumptions required for the calculations.

\section{Results}

Results of calculating the LCOE for PSHPP under three scenarios after applying different discount rates, as a function of investment capital cost, are plotted in Figs. 6, 7 and 8. It is clear from the figures that the relation is linear. To obtain the values of investment cost at which PSHPP is competitive to SCGT, the relationships have been expressed as a linear function through application of regression technique (Table 2).

Table 3 shows LCOE of SCGT at different discount rates in case of there is no increase in international fuel costs and in case of escalated international fuel costs.

\section{Pumping cost scenario 1}

Adopting the case that pumping cost is equal to the price of buying electricity from the Egyptian Unified Grid at off-peak time, when substituting by values in Table 3 with the corresponding regression equation in Table 2 it is found that PSHPP has competitiveness over SCGT power plants only in the escalated international fuel costs fuel scenario at $r 8,10$ and $12 \%$, provided that the capital cost for PSHPP should not exceed 2680.95, 2415.298 and $2211.146 \$ / \mathrm{kW}$, respectively. These milestones are shown clearly in Fig. 7 on the curves of different discount rates and it is noticed that on the curve $(r 8 \%)$ there is a tolerance of the capital cost of the PSHPP to range from $2200 \$ / \mathrm{kW}$ (minimum capital cost of any PSHPP assumed in this study) to $2679 \$ / \mathrm{kW}$, while on the curve where $r$ is assumed to be $12 \%$ the tolerance is very tight (2200-2222 \$/kW).

PSHPP's LCOE does not have any competitiveness over that of SCGT in the escalated international fuel cost scenario as a whole, and at $r 14 \%$ in the fixed fuel cost scenario (the points of intersection are out of PSHPP's capital cost range).

\section{Pumping cost scenario 2}

Take the assumption that the pumping cost is $70 \%$ (fuel portion cost) of the total energy payment cost in first scenario. When checking the possibility of intersection
Table 1 Summary of assumptions of the study

\begin{tabular}{|c|c|}
\hline \multicolumn{2}{|l|}{ Financial data } \\
\hline Installation cost excluding civil works & $1600 \$ / k W$ \\
\hline Civil work costs & $2400 \$ / \mathrm{kW}$ \\
\hline Interconnection costs & 12.80 M US\$ \\
\hline Water piping system & 20.0 M US\$ \\
\hline Fixed costs & $30.8 \$ / k W$-year \\
\hline Variable costs & 0 \\
\hline Escalation in O\&M & $3 \%$ \\
\hline Escalation in water price & $3 \%$ \\
\hline Base year of the study & 2015 \\
\hline Pumping electricity cost (off-peak) at $500 \mathrm{kV}$ & $0.0248 \$ / \mathrm{kWh}$ \\
\hline Selling price of generated electricity (on-peak) & $0.0511 \mathrm{EG} \$ / \mathrm{kWh}$ \\
\hline Capacity payment for intensive industries & $0.015 \$ / \mathrm{kW}$-month \\
\hline Exchange rate & 10 \\
\hline Tax rate & $0 \%$ \\
\hline Commitment fee & $0.5 \%$ \\
\hline Discount rate of the project & $10 \%$ \\
\hline \multicolumn{2}{|l|}{ Loan data } \\
\hline Foreign loan & $60 \%$ \\
\hline Term to repay & 20 years \\
\hline Grace period & 3 years \\
\hline Interest rate & $6 \%$ \\
\hline Local loan & $40 \%$ \\
\hline Term to repay & 10 years \\
\hline Grace period & 2 years \\
\hline Interest rate & $11 \%$ \\
\hline \multicolumn{2}{|l|}{ Technical data } \\
\hline Unit capacity & $350 \mathrm{Mw}$ \\
\hline Number of units & 6 units \\
\hline Project lifetime & 60 years \\
\hline Construction period & 5 years \\
\hline Cycle efficiency & $0.75 \%$ \\
\hline Scheduled maintenance & 20 days \\
\hline Forced outage rate & $0.05 \%$ \\
\hline Generating hours per day & 10 years \\
\hline Capacity factor & $34 \%$ \\
\hline Pumping efficiency & $0.95 \%$ \\
\hline Height (upper reservoir effective head) & $600 \mathrm{~m}$ \\
\hline Total expected annual generated energy & 6274 Gwh \\
\hline Total required pumping energy & 8365 Gwh \\
\hline Water flow rate & $376 \mathrm{~m}^{3} / \mathrm{s}$ \\
\hline Water capacity & $13.53 \mathrm{mcm}$ \\
\hline Evaporation rate in Suez Region & 3.4 m/year \\
\hline Losses of water per year & $3.65 \mathrm{mcm} /$ year \\
\hline Project total amount of water during construction & $104.6 \mathrm{mcm}$ \\
\hline Average grid fuel consumption (2013/2014) & $211 \mathrm{gm} / \mathrm{kWh}$ \\
\hline NG price & $3 \$ / \mathrm{MMBtu}$ \\
\hline Kwh generated fuel price & $8.37248 \mathrm{kWh}$ \\
\hline WACC & $8 \%$ \\
\hline
\end{tabular}




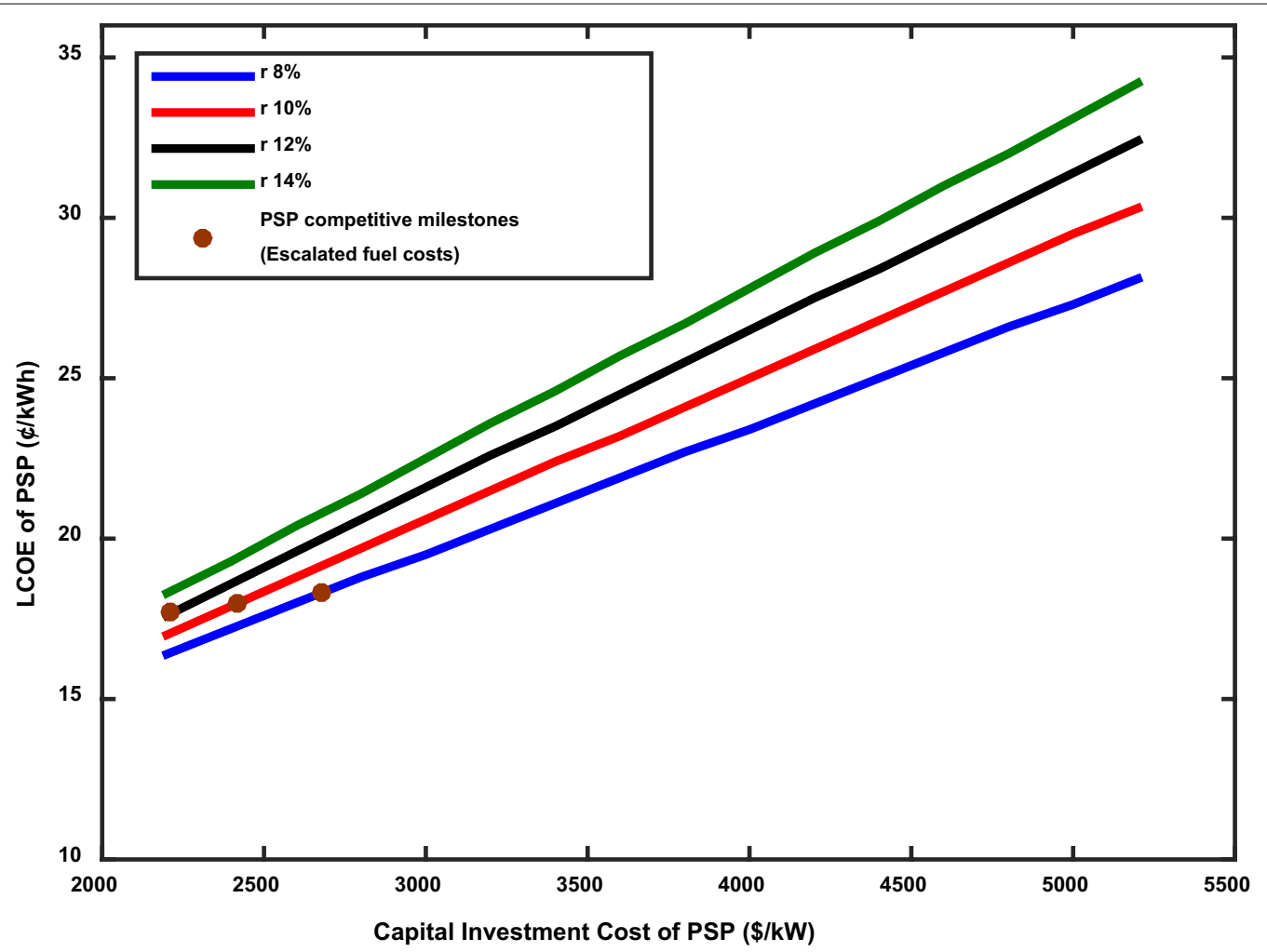

Fig. 7 LCOE of PSHPP versus variable capital cost at different discount rates (Scenario 1)

between LCOE values of PSHPP and those of SCGT (Fig. 8), it is found that PSHPP has competitiveness over SCGT power plants still only in the case of escalated international fuel costs, but in this scenario the range of the possibility of the capital cost is more flexible; also, its competiveness at $r 14 \%$ exists. PSHPP has competitiveness over SCGT power plants at $r 8,10,12$ and 14\% (Table 3), on condition that the capital cost for PSHPP should not exceed 3136.82, 2780.692, 2522.222 and $2325.425 \$ / \mathrm{kW}$, respectively.

\section{Pumping cost scenario 3}

From the intersection between LCOE values of PSHPP with those of SCGT (Fig. 9), it is found that at both fuel cost scenarios and all discount rates, PSHPP will have competitiveness over SCGT. For the fixed fuel cost scenario, the LCOE of PSHPP is more economical than that of SCGT provided that its capital cost does not exceed $2938.555,2616.615,2392.65$ and $2226.872 \$ / \mathrm{kW}$ at $r$ $8,10,12$ and $14 \%$, respectively. For the pessimistic fuel cost, its capital cost should not exceed 4179.67, 3629.11, 3246.991 and $2968.07 \$ / \mathrm{kW}$ for the same discount rates. This is an upgrade in competiveness from the above both scenarios, and the range of tolerance of PSHPP capital cost in the escalated fuel cost scenario reached about 4180 \$/kW.

\section{Conclusion}

In this manuscript, a simplified approach to define the conditions at which PSHPP has competitiveness over SCGT power plants. PSHPPs have many additional features of their operation in the common grid whose cost estimate cannot be represented so easily.

It can be concluded from the results that PSHPP does not have an absolute economic competitiveness compared with SCGT power plant, but the economic viability of constructing PSHPP is variable according to different factors and conditions. From the perspective of electricity sector in Egypt, as long as the government subsidizes the fuel prices supplied to SCGT power plants, there will be no need to construct PSHPP in Attaqa Mountain.

The pure economic competitiveness of PSHPP over SCGT power plant will appear in case of using the international fossil fuel prices and taking into account the huge amounts of foreign currency to import such fossil fuels to cover the domestic demand from fuel in other 


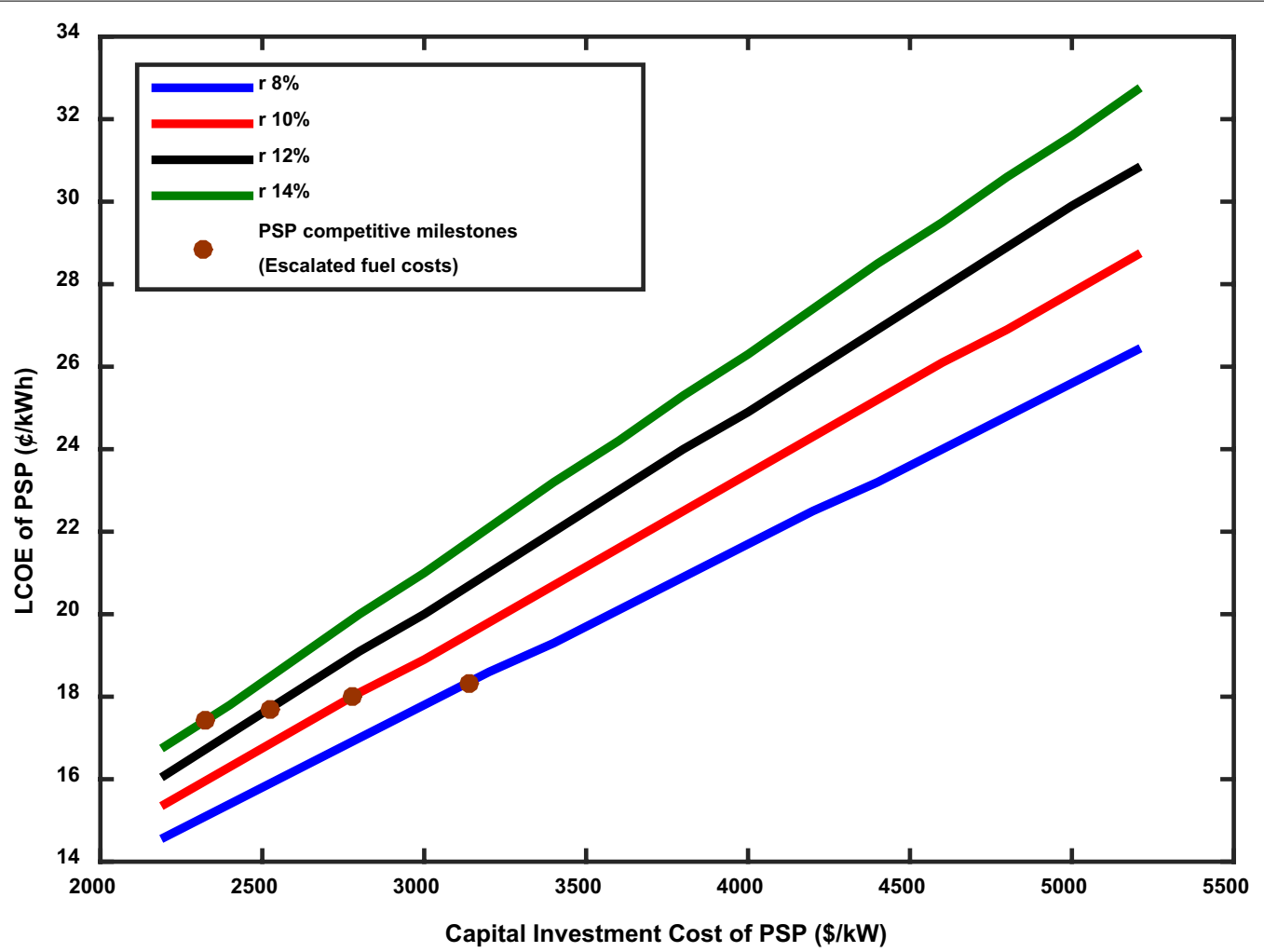

Fig. 8 LCOE of PSHPP versus variable capital cost at different discount rates (Scenario 2)

Table 2 Constants derived for each pumping scenario and discount rate

\begin{tabular}{|c|c|c|}
\hline Pumping cost scenario & $r(\%)$ & Regression equation \\
\hline \multirow[t]{4}{*}{ Scenario 1: pumping cost is equal to the price of buying electricity from the Egyptian Unified Grid at off-peak time } & 8 & $I=25650$ LCOE -2013 \\
\hline & 10 & $I=22510 \mathrm{LCOE}-1632$ \\
\hline & 12 & $I=20340$ LCOE -1387 \\
\hline & 14 & $I=18870$ LCOE -1246 \\
\hline \multirow[t]{4}{*}{ Scenario 2: pumping cost is $70 \%$ (fuel portion cost) of the total energy payment cost in first scenario } & 8 & $I=25540 \mathrm{LCOE}-1537$ \\
\hline & 10 & $I=22540 \mathrm{LCOE}-1272$ \\
\hline & 12 & $I=20380$ LCOE -1083 \\
\hline & 14 & $I=18850 \mathrm{LCOE}-963.9$ \\
\hline \multirow[t]{4}{*}{ Scenario 3: pumping cost is assumed to be zero } & 8 & $I=25590$ LCOE -503.3 \\
\hline & 10 & $I=22450 \mathrm{LCOE}-407.4$ \\
\hline & 12 & $I=20390$ LCOE -360 \\
\hline & 14 & $I=18860$ LCOE -323 \\
\hline
\end{tabular}

Table 3 LCOE of SCGT at different discount rates and in the two fuel scenarios

\begin{tabular}{|c|c|c|c|c|}
\hline \multirow[t]{2}{*}{ Fuel cost scenario } & \multicolumn{4}{|c|}{$\begin{array}{l}\text { LCOE of SCGT at different } r(\mathrm{C} / \\
\mathrm{kWh} \text { ) }\end{array}$} \\
\hline & $r: 8 \%$ & $r: 10 \%$ & $r: 12 \%$ & $r: 14 \%$ \\
\hline Fixed international fuel costs & 13.45 & 13.47 & 13.5 & 13.52 \\
\hline Escalated international fuel costs & 18.3 & 17.98 & 17.69 & 17.45 \\
\hline
\end{tabular}

sectors than electricity sector. This competitiveness of PSHPP can be increased also by decreasing the pumping cost to lift water up in PSHPP, which is a strategic decision by the government. PSHPP competitiveness over SCGT technology increases more when the limitations and conditions at which installing PSHPP in Egypt are more relaxed. Therefore, ideally, there should be a double tariff structure mechanism designed to get the 


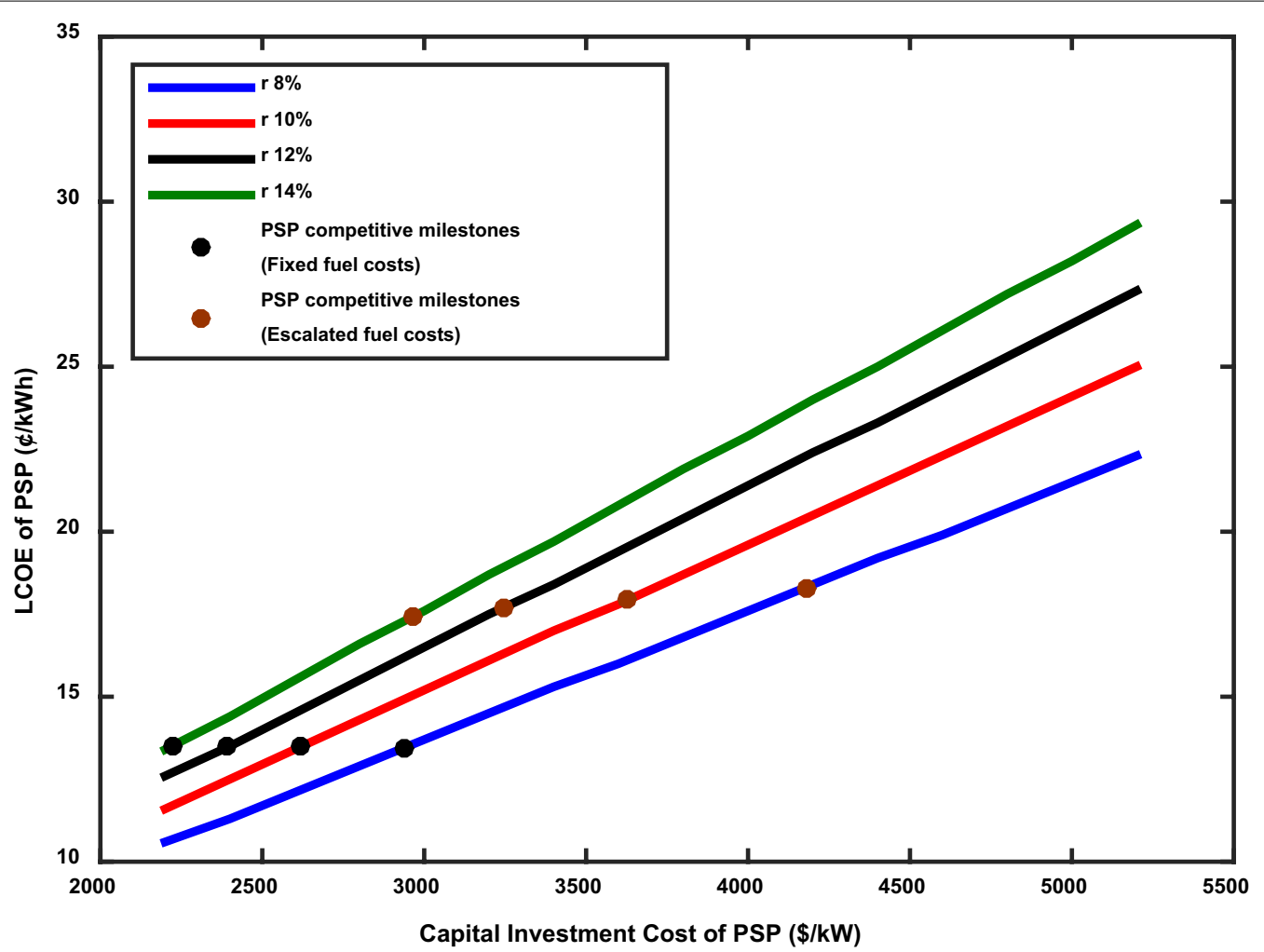

Fig. 9 LCOE of PSHPP versus variable capital cost at different discount rates (Scenario 3)

advantages of PSHPPs as a clean energy source to maximize its benefits.

\section{Authors' contributions}

DA took part in compiling the required data, conducting the literature review, programming the mathematical model, verifying its accuracy, running the program, plotting the results, writing some parts of the paper and placing it in the required format for publication. RA determined the methodology and selected the research tools, and was involved in organizing the scenarios required to simulate, analyzing the results, code error debugging, results verification, reviewing the paper in terms of form and content, writing some parts and following up the publication of the paper. AMl proposed the research topic and general approach, reviewed the methodology and approved the scenarios to be simulated and verified the results and reviewed language and terminology used in the text. EAE performed approving the research topic and general approach, reviewing and verification of the results, and final review of language and terminology used in the text. All authors read and approved the final manuscript.

\section{Author details}

${ }^{1}$ Egyptian Electricity Holding Company (EEHC), Ministry of Electricity and Renewable Energy, Cairo, Egypt. ${ }^{2}$ National Water Research Center (NWRC), Ministry of Water Resources and Irrigation, El Qanatir, Egypt. ${ }^{3}$ Electrical Power and Machines Department, Faculty of Engineering, Cairo University, Giza, Egypt.

\section{Competing interests}

The authors declare that they have no competing interests.

\section{Availability of data and materials}

All data and materials are presented in the main paper.

\section{Funding}

Not applicable.

\section{Publisher's Note}

Springer Nature remains neutral with regard to jurisdictional claims in published maps and institutional affiliations.

Received: 26 November 2017 Accepted: 21 February 2018

Published online: 01 March 2018

\section{References}

Barbour, E., Wilson, I. G., Radcliffe, J., Ding, Y., \& Li, Y. (2016). A review of pumped hydro energy storage development in significant international electricity markets. Renewable and Sustainable Energy Reviews, 61, 421-432.

Baxter, R. (2006). Energy storage: A nontechnical guide. Houston: PennWell Books.

Black \& Vetch Consultancy Company. (2012). Cost and performance data for power generation technologies prepared for the national renewable energy laboratory, Cost Report, February 2012. https://www.bv.com/ docs/reports-studies/nrel-cost-report.pdf. Accessed 2016.

Breeze, P. (2014). Chapter 10: Power system energy storage technologies. In Power generation technologies (pp. 195-221). Oxford: Newnes.

Deloitte. (2014). Some common mistakes to avoid in estimating and applying discount rates, A middle east point of view. Discount rates report. https:// www2.deloitte.com/content/dam/Deloitte/xe/Documents/AboutDeloitte/mepovdocuments/mepov13/dtme_mepov13_Discount\%20 rates.pdf. Accessed 2016.

Ebasco Overseas Corporation. (1993). Feasibility study of a pump storage hydroelectric power station, Egypt, Final Phase 1 Report, September 1993.

Edgell, H. S. (2006). Arabian deserts: Nature, origin and evolution. Netherlands: Springer.

Egyptian Electric Utility and Consumer Protection Regulatory Agency (EgyptERA). (2015). Electricity tariff [Internet]. www.Egyptera.org. Accessed 2016. 
Egyptian Electricity Holding Company (EEHC). (2015). Annual report 2014/2015 [Internet]. Arab Republic of Egypt, Ministry of Electricity and Renewable Energy. http://www.moee.gov.eg/english_new/EEHC_ Rep/2014-2015en.pdf. Accessed 2016.

ICIS. (2016). Natural gas prices, markets \& analysis [Internet], ICIS. https://www. icis.com/. Accessed 2016.

Insee. (2016). International prices of imported new materials [Internet]. National Institute of Statistics and Economic Studies. https://www.bdm. insee.fr/bdm2/affichageSeries?idbank=001642883\&page=tableau\&requ est_locale=en. Accessed 2016.

International Electro-Technical Commission (IEC). (2011). Electrical energy storage - White paper, Geneva, Switzerland. http://www.iec.ch/whitepaper/ energystorage/. Accessed 2016.

International Energy Agency (IEA). (2014). Technology roadmap energy storage [Internet]. France: OECD/IEA. http://www.iea.org/publications/ freepublications/publication/technologyroadmapenergystorage.pdf. Accessed 2016.

International Renewable Energy Agency (IRENA). (2012). Renewable energy technologies: cost analysis series. Hydropower [Internet]. Power Sector, June 2012. Report No. 1(3/5). https://www.irena.org/documentdownloads/publications/re_technologies_cost_analysis-hydropower.pdf. Accessed 2016.

Kaplan, S. (2008). Power plants: Characteristics and costs [Internet]. Congressional Research Services. Report No. RL34746. https://fas.org/sgp/crs/ misc/RL34746.pdf. Accessed 2016.

Our World of Energy (OWOE). (2014). Other renewables energy — What is pumped hydroelectric storage? [Internet]. Our World of Energy. http:// www.ourworldofenergy.com/vignettes.php?type=other-renewablesenergy\&id=10. Accessed July 2014.
Rognlien, L. (2012). Pumped storage development in Ovre Otra, Norway, Norwegian University of Science and Technology. https://daim.idi.ntnu. no/masteroppgaver/007/7996/masteroppgave.pdf.

Sandia National Laboratories. (2016). DOE global energy storage database [Internet]. United States of America: Office of Electricity Delivery \& Energy Reliability. www.energystorageexchange.org. Accessed 2016.

Swedish Consultants (SWECO). (1997). Mount Attaqa pumped storage project feasibility study. Final report, Stockholm, Sweden.

Thapar, O. D. (2002). Chapter 2: Techno-economic studies for capacity and unit size of hydro electric schemes. In Modern hydroelectric engineering practice in India: Electro-mechanical works (pp. 13-52). http://www.iitr. ac.in/departments/AH/uploads/File/Modern_Hydroelectric_Engineering_Practice_Prof_OD_Thapar/Nolume_I/Chapter-2_Techno-Economic_ Studies_for_Capacity_and_Unit_Size_of_Hydro_Electric_Schemes.pdf. Accessed 15 July 2016.

Trading Economics. (2016). United States Consumer Price Index (CPI) [Internet] Trading Economics. http://www.tradingeconomics.com/united-states/ consumer-price-index-cpi. Accessed 2016.

U.S. Energy Information Administration (EIA). (2013). Updated capital cost estimates for utility scale electricity generating plants [Internet]. United States of America: U.S. Department of Energy. Report No. 20585. http:// www.eia.gov/outlooks/capitalcost/pdf/updated_capcost.pdf. Accessed 2016.

U.S. Energy Information Administration (EIA). (2016). How much coal, natural gas, or petroleum is used to generate a kilowatthour of electricity? [Internet]. United States of America: U.S. Department of Energy. https://www. eia.gov/tools/faqs/faq.cfm?id=667\&t=6. Accessed 2016.

\section{Submit your manuscript to a SpringerOpen ${ }^{\circ}$ journal and benefit from:}

- Convenient online submission

- Rigorous peer review

- Open access: articles freely available online

- High visibility within the field

- Retaining the copyright to your article

Submit your next manuscript at $\boldsymbol{\nabla}$ springeropen.com 